\section{Commentary: Another way to skin a rare and dangerous cat}

\author{
Robert D. B. Jaquiss, MD
}

In patients born with pulmonary valve atresia with intact ventricular septum (PA/IVS), right heart structures may be so hypoplastic that biventricular circulation cannot be achieved. ${ }^{1}$ In the most unfavorable manifestation of PA/IVS, the epicardial coronary arteries are stenotic (or proximally atretic) such that a significant amount coronary arterial flow is provided by the hypoplastic and hypertensive right ventricle via sinusoidal connections to the coronary arteries. This condition is termed "right ventricular dependent coronary circulation" (RVDCC), the most extreme form of which is bilateral coronary ostial atresia. ${ }^{2}$ In many centers, patients with PA/IVS with RVDCC are directed toward cardiac transplantation rather than singleventricle palliation culminating in the Fontan circulation. ${ }^{3}$ Patients with RVDCC are at high risk of sudden death, particularly in the first few months of life, when pulmonary blood flow is provided by either a patent ductus arteriosus or a systemic to pulmonary shunt (SPS) with consequent diastolic hypotension. Often such patients demonstrate electrocardiographic evidence of myocardial ischemia, sometimes accompanied by elevations in serum levels of troponin or other markers of cardiomyocyte injury.

One approach to address the coronary insufficiency in RVDCC is to provide "antegrade" blood flow to the right ventricular cavity by creation of an aorto-right ventricle shunt (ARVS). This was initially described in an older child at the time of Fontan completion. ${ }^{4}$ Later, a small series was reported with placement of ARVS in 5 children at varying ages, the youngest of whom was 6 weeks of age and

\footnotetext{
From the Division of Pediatric Cardiothoracic Surgery, Department of Thoracic and Cardiovascular Surgery, University of Texas Southwestern Medical Center and Children's Medical Center, Dallas, Tex.

The author reported no conflicts of interest.

The Journal policy requires editors and reviewers to disclose conflicts of interest and to decline handling or reviewing manuscripts for which they may have a conflict of interest. The editors and reviewers of this article have no conflicts of interest.

Received for publication Feb 11, 2021; revisions received Feb 11, 2021; accepted for publication Feb 22, 2021; available ahead of print Feb 27, 2021.

Address for reprints: Robert D. B. Jaquiss, MD, Children's Medical Center, 1935 Medical District Dr, Dallas, TX 75235 (E-mail: robert.jaquiss@utsouthwestern. edu).

JTCVS Techniques 2021;7:222-3

2666-2507

Copyright (c) 2021 The Authors. Published by Elsevier Inc. on behalf of The American Association for Thoracic Surgery. This is an open access article under the CC BY license (http://creativecommons.org/licenses/by/4.0/).

https://doi.org/10.1016/j.xjtc.2021.02.033
}

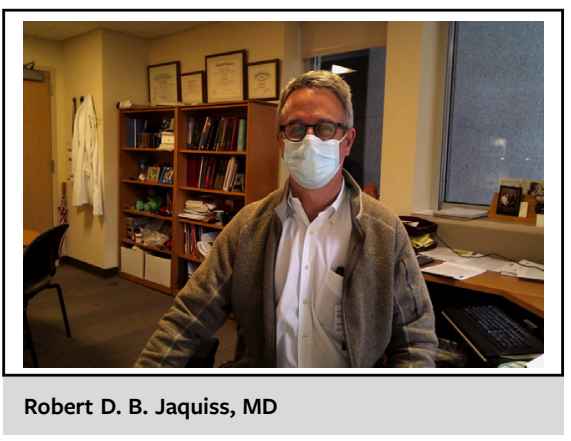

CENTRAL MESSAGE

In pulmonary atresia/intact septum with bilateral coronary ostial atresia, antegrade coronary blood flow may be optimized by an aorto-right ventricular shunt, to the free wall or tricuspid annulus.

manifested coronary ischemia a few weeks after an SPS. More recently, Sakurai and colleagues ${ }^{6}$ described simultaneous placement of SPS and ARVS in a 6-week-old patient with bilateral coronary ostial atresia and ongoing myocardial ischemia.

In the present report, Said and colleagues ${ }^{7}$ described, in a similar patient, modifications of this approach, which provided bridge to transplant, albeit not without interval complications (2 separate courses of extracorporeal membrane oxygenation). Their modifications included anastomosis of the ARVS to the tricuspid annulus (after valvectomy) via the right atrium, and employment of allograft saphenous vein as conduits for both the ARVS and the SPS. The authors suggest that avoidance of anastomosis to the thickened right ventricular wall is preferrable to avoid anastomotic obstruction. However, such obstruction has not been reported in ARVS to date, and the widespread use of similar anastomoses in the modified Norwood operation suggests that most neonatal surgeons have overcome this issue. While anastomosis to the tricuspid annulus eliminates concern about tricuspid regurgitation after ARVS, closing the orifice with a patch as described by Sakurai and colleagues would seem to accomplish the same goal in a simpler fashion. Finally, the suggested superiority of allograft conduit in comparison with expanded polytetrafluoroethylene conduit remains speculative, in either SPS or ARVS application, and at present remains a "surgeon's choice" matter. Despite these minor quibbles, I applaud the authors for an inventive and 
skillful solution to an admittedly rare but potentially lethal variant of congenital heart disease.

\section{References}

1. Daubeney PE, Delany DJ, Anderson RH, Sandor GG, Slavik Z, Keeton BR, et al. United Kingdom and Ireland Collaborative Study of Pulmonary Atresia with Intact Ventricular Septum. Pulmonary atresia with intact ventricular septum: range of morphology in a population-based study. J Am Coll Cardiol. 2002;39:1670-9.

2. Powell AJ, Mayer JE, Lang P, Lock JE. Outcome in infants with pulmonary atresia, intact ventricular septum, and right ventricle-dependent coronary circulation. Am J Cardiol. 2000;86:1272-4. A9.

3. Guleserian KJ, Armsby LB, Thiagarajan RR, del Nido PJ, Mayer JE Jr. Natural history of pulmonary atresia with intact ventricular septum and right-ventricle- dependent coronary circulation managed by the single-ventricle approach. Ann Thorac Surg. 2006;81:2250-7.

4. Freeman JE, DeLeon SY, Lai S, Fisher EA, Ow EP, Pifarré R. Right ventricle-toaorta conduit in pulmonary atresia with intact ventricular septum and coronary sinusoids. Ann Thorac Surg. 1993;56:1393-5.

5. Laks H, Gates RN, Grant PW, Drant S, Allada V, Harake B. Aortic to right ventricular shunt for pulmonary atresia and intact ventricular septum. Ann Thorac Surg. 1995;59:342-7.

6. Sakurai H, Sakurai T, Ohashi N, Nishikawa H. Aortic to right ventricular shunt for pulmonary atresia with intact ventricular septum and bilateral coronary ostial atresia. J Thorac Cardiovasc Surg. 2018;156:e17-20.

7. Said SM, Marey G, Greene R, Griselli M, Hiremath G, Aggarwal V, et al. The double shunt technique as a bridge to heart transplantation in a patient with pulmonary atresia with intact septum and right ventricular-dependent coronary circulation. J Thorac Cardiovasc Surg Tech. 2021;7:216-21. 